\section{LUMINESCENCE OF SOLIDS}

An Introduction to Luminescence of Solids

By Humboldt W. Leverenz. Pp. xv+569. (New York : John Wiley and Sons, Inc.; London: Chapman and Hall, Ltd., 1950.) 96s. net.

$\mathrm{P}$ HOSPHORS are now manufactured by hundreds of tons a year, the amount having increased ten-fold with the development of fluorescent lighting. Television and radar use quantities of the order of twenty tons a year of more exacting phosphors, and there are other uses for X-ray screens, self-luminous radioactive paints, and luminous plastics and tapes for a variety of purposes. With the increasing availability in reproducible forms, since they are difficult to make on the small scale, ingenious devices employing them are likely to increase in the future.

There are two ways of developing a theory of phosphors. One that has been very popular is to begin from the ideas used for explaining the properties of semi-conductors, which lead to generalized concepts such as 'activator centres', 'electron traps', 'excitons', 'phonons', etc. This method treats the crystal as a whole and is helpful in attempts to understand how energy can pass from the nonluminescent bulk to particular centres from which emission occurs. The other method is to emphasize the essentially atomic or molecular nature of the luminescence as shown by uranyl salts or aromatic hydrocarbons, for example, the fluorescence of which scarcely changes from solid to solution, and to focus attention more on the nature of the emitter as a chemical particle than as something irregular in the ideal lattice of an 'impurity-activated' phosphor.

In early work the identification of the emitters was obscured by the fact that incredibly small amounts of impurities sometimes exerted a dominating effect ; in this book Dr. H. W. Leverenz here defines ideal 'luminescence purity' as 99.9999 per cent and 'spectroscopic purity' as 99.999 per cent. There are now signs, however, that the fashion is changing, as in other fields, with a swing away from communal electronic physical theories to individualistic chemical interpretations, where considerations of atomic volume and variable valency are significant.

The book is the fruit of twenty years of experience on the preparation of phosphors of all types. The author is an outstanding authority, well conversant with every side of physics and chemistry related to the subject, cautious, accurate and systematic. $\mathrm{He}$ states, "During the alchemical infancy and haphazard growth of the phosphor art, the resultant desultory and greatly dispersed literature on luminescence of solids has become cluttered with confused terminologies, incorrect data, and baneful misconceptions. As an antidote this book seeks to be objective, to provide a rational terminology, and to furnish a critical guide to the literature". In seeking for accuracy of definitions and statement, the author has allowed his style to become somewhat ponderous. $\mathrm{He}$ first builds up a massive apparatus of physical theory, only to show in the end to what little quantitative purpose it can be put. After advanced considerations of energy-levels in imperfect crystals, he dismisses the simpler concept of potential energy curves as "artistically stimulating ; some may incorporate verity, but they have yet to achieve practical significance". Finally, after all the elaborations of physical theory, he states: "At present, in the absence of a satisfactory compilation of phosphors and phosphor properties, it is usually necessary to enlist the aid of a phosphor expert with broad experience in order to assure obtention of the best available phosphor for a particular purpose".

This is an extremely valuable book for all workers on luminescence, containing matter, not obtainable elsewhere, on every aspect of theory, methods of phosphor manufacture, different types of phosphor and their detailed uses, modes of excitation, decay characteristics, etc., with a multitude of precise definitions and physical data. Although entitled an "Introduction" and therefore expressing only a fraction of the author's own knowledge and experience, it is, in fact, a very extensive and detailed account which will absorb the full attention of one coming newly to the subject.

F. J. BOWEN

\section{WORLD POPULATION AND FOOD}

\section{Geography of Hunger}

By Josué de Castro. Pp. 288. (London: Victor Gollancz, Ltd., 1952.) 18s. net.

F the three historic checks on population growth -war, famine and pestilence-the last-named is being dramatically curtailed by modern techniques. The ensuing population increase is both sudden and immense, and it is presenting the world with one of the biggest problems it has ever had to face, that of providing food (and other necessities) for this rapidly increasing multitude.

The author of this book believes firmly that enough food could be produced and that only the will is lacking. He cites examples from all parts of the world to show that malnutrition and frank hunger are widespread even now ; but he lays the blame for this squarely at the door of Western European civilization with its domination over the 'backward areas'. Much of his criticism is valid; but the exploitation of man by man is by no means the only factor which limits the world's food supply, and no one should read this book without also reading Vogt's "Road to Survival" and Cook's "Human Fertility".

The author dismisses as "alarmist" those who press the need for a voluntary control of population increase to replace the harsh, natural checks; but he has the grace to remind his readers that "the United States of America, using fertilizers on a scale without precedent in the history of agriculture, has already exhausted 100 million acres of land in less than two centuries of cultivation".

There can be little doubt but that many apparently successful measures merely postpone the day of reckoning while adding to the bill to be paid, and it is unfortunate that this book has been published at a time when its author is chairman of the executive of the Food and Agriculture Organization, as this gives it an air of quite unwarranted authority. (It is not, of course, in any way an official publication.) The evidence presented has been collected by means of "a widespread correspondence" and "talks with strategically placed personalities" and, inevitably, not all of it rings true. Few countries are fully documented with regard to their vital statistics, food production, economic resources, etc., and many of the figures which the author uses are, at best, no more than informed guesses; they provide a very insecure base for the rather fantastic edifice he builds upon them; but the general reader may not realize this, and false beliefs and false hopes will be engendered. 